\title{
UPAYA SKRINING DINI STUNTING MELALUI PEMBERDAYAAN KADER DAN PENINGKATAN PENGETAHUAN IBU TENTANG GIZI BALITA
}

\author{
Nilatul Izah' ${ }^{1)}$, Seventina Nurul Hidayah²), Iroma Maulida ${ }^{3)}$ \\ Program Studi D III Kebidanan, Politeknik Harapan Bersama
}

\begin{abstract}
Abstrak
Stunting memberikan gambaran adanya status gizi yang kurang dan kronik saat masa tumbuh kembang dari awal kehidupan yaitu 1000 hari awal pertama kehidupan atau HPK. Perhatian ibu terkait panjang dan tinggi badan balita perlu dipantau sejak dini sehingga ketahuan jika ada ketidaknormalan pada balita. Deteksi lebih awal akan mencegah penyimpangan yang berkelanjutan sehingga perlu pemberian terapi untuk hasil yang lebih baik tanpa ada hal yang tidak diinginkan dalam tumbuh kembang balita. Dalam menyelesaikan masalah dimasyarakat khususnya dalam mengatasi masalah gizi balita yaitu kasus stunting tim pengabdian pada masyarakat memberikan pendidikan kesehatan gizi balita pada ibu balita serta memberikan pelatihan pada kader bagaimana melakukan srining dini terhadap kejadian stunting. Kegiatan pengabdian pada masyarakat dalam upaya skrinng dini stunting melalui pemberdayaan kader dan peningkatan pengetahuan ibu dalam memenuhi kebutuhan gizi balita di Desa Pesarean Kecamatan Pagerbarang Kabupaten Tegal. Pengabdian masyarakat dilaksanakan dalam 2 hari yaitu pada tanggal 2 Desember 2019 dilaksanakan pemberian pendidikan kesehatan tentang gizi bagi ibu balita. Tanggal 3 Desember 2019 dilaksanakn kegiatan pendidikan kesehatan dan pelatihan pada kader tentang pemeriksaan antopometri dan penilaian status gizi balita, pada pelatihan para kader diberikan aplikasi untuk mendeteksi status gizi balita sehingga dapat dijadikan sebagai usaha utama deteksi stunting. Hasil pengabdian masyarakat yaitu ada peningkatan pengetahuan bagi ibu balita yang ikut posyandu balita sebagai upaya dalam mencegah stunting pada balita, terdapat peningkatan pengetahuan serta keterampilan kader dalam melakukan pemeriksaan antopometri pada balita dalam upaya melakukan skrining stunting.
\end{abstract}

Kata kunci: Skrining Dini Stunting, Gizi Balita

\begin{abstract}
Stunting illustrates the chronic malnutrition status during growth and development since the beginning of life, namely 1000 days of life (HPK) Growth monitoring, especially body length and / or height, should be done since the newborn to assess growth is normal. Early detection of growth deviations is needed for early treatment, thus providing better results and preventing the occurrence of undesirable risks. In solving problems in the community, especially in overcoming toddlers' nutrition problems, namely the incidence of stunting in infants, the community service team provides nutrition health education for toddlers to toddlers mothers and provides training to cadres on how to conduct early screening of stunting events. Community service activities in the efforts of early screening stunting through empowering cadres and increasing knowledge of mothers in meeting the nutritional needs of children under five in Pesarean Village, Pagerbarang District, Tegal Regency. Community service is carried out within 2 days, namely on December 2, 2019, providing health education to mothers of children under five about nutrition to children under five. On 3 December 2019 health education and training activities for adres on antopometry examinations and assessment of nutritional status of children under five. In the training, cadres were given a toddler growth and development application that could be used to detect the nutritional status of toddlers so that they could be used as an initial attempt at early screening for stunting in infants. The results of community service there is an increase in the knowledge of mothers of children under five who take part in activities especially increasing knowledge about nutrition for toddlers as an effort to prevent stunting in infants, there is an increase in knowledge and skills of cadres in conducting antopometry checks on toddlers in an effort to detect early toddlers who are stunted
\end{abstract}

Keywords: Early Screening Stunting, Toddler Nutrition.

Correspondence author: Nilatul Izah, nilaizah12@gmail.com, Tegal, Indonesia

This work is licensed under a CC-BY-NC 


\section{PENDAHULUAN}

Stunting memperlihatkan status gizi yang sifatnya kronik pada balita saat 1000 hari awal kehidupan yang diakibatkan ketidaksesuaian sumber gizi yang dapat memenuhi kebutuhan tumbuh kembang balita di masa itu. Keadaan ini memiliki nilai z-score (TB/U) kurang -2 SD sesuai standar pertumbuhan WHO. Di Dunia diperkirakan 1 dari 4 balita alami stunting. Adanya kekurangan gizi mengakibatkan kematian, mudah sakit atau postur yang kurang normal dari usianya. Selain itu kejadian sunting dapat pula berakibat kemampuan kognitif menjadi berkurang. Indonesia menduduki peringkat 4 setelah India sekitar 48,3 juta, Pakistan serta Nigeria 10 juta dilanjutkan Indonesia 8,8 juta namun masih jauh dari sasaran RPJMN 2019 yaitu 28\% untuk penurunan kasus stunting. Meskipun ada penurunan kasus sunting namun tidak bermaksud kejadian sunting telah teratasi (Timnas Penanggulangan Kemiskinan, 2017). Prevalensi stunting di Jawa Tengah tergolong tinggi yaitu sebesar 33,6\% dengan perincian $17 \%$ anak pendek dan $16,9 \%$ anak sangat pendek. Wilayah Wanasari memiliki prevalensi tinggi kejadian stunting se Jawa Tengah.

Stunting berhubungan dengan resiko kesakitan serta kematian, hambatan perkembangan motorik dan mental sehingga perlu mendapatkan perhatian khusus agar tidak menimbulkan resiko yang dapat merugikan hasil akhir tumbuh kembang anak saat dewasa nanti. Maka pantauan TB dan BB balita harus diperhatikan sejak bayi. Deteksi awal adanya penyimpangan sangat dibutuhkan untuk memberikan terapi dini sehingga harapannya akan memiliki hasil yang lebih baik dan resikoyang dapat merugikan anak seperti masalah mental, kurang dalam kemampuan motorik dan lemah fisik dapat diatasi lebih dini. Pengukuran panjang dan tinggi badan perlu diukur secara berkala, dimulai saat bayi baru lahir, usia 1, 2, 3, 4, 5, 6 bulan dan seterusnya. Pemeriksaan kesehatan dan pertumbuhan anak di Desa Wanasari dilakukan dengan kegiatan Posyandu yang dilakukan setiap satu bulan sekali. Program Posyandu dilakukan di setiap desa oleh kader yang telah diberi pengetahuan dan pelatihan.

Tujuan melibatkan kader yang menjadi pelaksana posyandu yaitu mensosialisasikan pengetahuan berkaitan dengan kesehatan, salah satunya tentang tumbang (Timnas percepatan penanggulangan miskin, 2017). Deteksi awal untuk tahu hambatan tumbuh kembang anak belum diberikan sehingga upaya preventif dengan tujuan mengatasi suatu hambatan perkembangan belum dilakukan. Pengabdian Kepada Masyarakat (PKM) ini dilaksanakan melalui peningkatan peran serta kader kesehatan melalui kegiatan pemberdayaan yang berlokasi di Puskesmas Pagerbarang. Melalui kegiatan PKM ini harapannya pengetahuan, pemahaman serta kewaspadaan para kader kesehatan mengenai kejadian stunting dapat meningkat sehingga memiliki kemampuan dalam upaya pecegahan dan penanggulangannya. Selain itu pada kegiatan PKM ini juga dilakukan kegiatan dalam upaya peningkatan pengetahuan orang tua balita tentang pemenuhan gizi pada balita sehingga kegiatan skrining kejadian stunting di wilayah tersebut dapat dilakukan secara dini dan menyeluruh tidak hanya pada kader kesehatan akan tetapi pada orang tua. Umumnya posyandu yang terdiri dari kegiatan menimbang, dan lebih fokus pada tahap pertumbuhan sehingga jika ada hambatan segera terdeteksi sebagai tindakan preventif.

Berdasarkan hasil penelitian yang pelaksana lakukan sebelumnya bahwa analisis sebaran dan determinan stunting dipengaruhi oleh riwayat penyakit infeksi, pemberian ASI secara eksklusif, pengetahuan gizi, usia ibu, dan TB dan BB orang tua balita. Desa pesarean merupakan salah satu desa diwilayah Kerja Puskesmas Pagerbarang dimana di desa pesarean masih terdapat balita yang mengalami gizi buruk serta stunting. 
Studi pendahuluan yang dilakukan menunjukkan kurangnya pengetahuan warga mengenai gizi pada balita dan kurang terlatihnya kader dalam melakukan screening stunting. Kegiatan ini bertujuan memberi pemahaman pada ibu balita tentang gizi balita. Selain itu pengebdian masyarakat ini bertujuan memberikan pemahaman dan keterampilan pada kader tentang stunting dan dan cara melakukan deteksi dini terhadap stunting Dalam menyelesaikan masalah dimasyarakat khususnya dalam mengatasi masalah gizi balita yaitu stunting maka tim pengabdian pada masyarakat dari Prodi D III Kebidanan tergerak untuk melakukan kegiatan dengan memberikan pendidikan kesehatan gizi balita pada ibu balita serta memberikan pelatihan pada kader bagaimana melakukan srining dini terhadap kejadian stunting. Penelitian yang berjudul Beberapa faktor yang berkaitan dengan Status Gizi Balita Stunting. Penelitian ini menggunakan desain Cross Sectional, dengan populasi penelitian yaitu balita usia 12 - 60 bulan di Desa Kembangan Kecamatan Kebomas Kabupaten Gresik. Hasil penelitian menunjukkan bahwa faktor umur, jenis konsumsi, tingkat kehadiran ke posyandu, frekuensi sakit dan lama sakit berhubungan secara bermakna dengan kasus sunting balita.

Penelitian dengan judul Pola Makan, Status sosial, Ekonomi Keluarga serta Prestasi Belajar anak dengan Stunting Usia 9 -12 tahun di Semarang Timur. Penelitian ini gunakan rancangan Cross sectional dengan 85 responden yaitu usia $9-12$ tahun. Hasil penelitian menyimpulkan bahwa tidak terdapat hubungan antara pola makan dengan prestasi usia 9- 12 bulan dikelurahan kemijen semarang Timur ( $\mathrm{p}$ value $>0,05$ ), selain itu tidak terdapat juga hubungan antara status sosial, ekonomi keluarga, dengan prestasi belajar anak yang mengalami sunting usia $\quad 9-12$ bulan di Kelurahan Kemijen Semarang Timur ( $\mathrm{p}$ value $>0,05$ ). Penelitrian tentang faktor resiko sunting pada anak berumur 2-3 tahun di Kecamatan Semarang Timur.

Penelitian ini merupakan penelitian dengan desain casecontrol dengan sampel ibu dengan anak stunting dan anak normal dengan usia $2-3$ tahun. Hasil mulrivariat menunjukkan bahwa faktor sunting yaitu status sosial ekonomi tergolong rendah $(\mathrm{P}=0,032$ : $\mathrm{OR}=4,13)$ sedangkan $\mathrm{PB}$ lahir, $\mathrm{TB}$ orang tua dan pendidikan orang tua bukan termasuk resiko.

Status ekonomi rendah adalah faktor resiko yang berkaitan dengan kejadian stunting dengan resiko 4,13 kali yang alami stunting

\section{METODE PELAKSANAAN}

Pelaksanaan kegiatan pengabdian kepada masyarakat yaitu tanggal 2 dan 3 Desember 2019. Kegiatan dilaksanakan selama 2 hari, hari pertama tanggal 2 Desember 2019 dilaksanakan di Kelompok Bermain Al - Amin Desa Pesarean Kecamatan Pagerbarang Kabupaten Tegal. Hari kedua dilaksanakan pada tanggal 3 Desember 2019 dilaksanakan di Balaidesa Pesarean Kecamatan Pagerbarang Kabupaten Tegal dengan menyelenggarakan pendidikan kesehatan mengenai gizi balita dan persiapan LCD dan alat peraga Food mode. Hari kedua kader diberi pelatihan periksa antopometri dan sekaligus diajarkan cara hitung status gizi berdasar z sore. Selain itu para kader juga diberikan aplikasi tumbang balita agar dapat lebih mudah menentukan status gizi balita.

\section{HASIL DAN PEMBAHASAN}

Kegiatan PKM dalam upaya skrinng dini stunting melalui pemberdayaan kader dan peningkatan pengetahuan ibu dalam memenuhi kebutuhan gizi balita di Desa Pesarean Kecamatan Pagerbarang Kabupaten Tegal. Pengabdian masyarakat dilaksanakan dalam 2 hari yaitu pada tanggal 2 Desember 2019 dilaksanakan pemberian pendidikan kesehatan 
yang dilaksanakan di Kelompok Bermain Al-Amin Desa Pesarean Kecamatan Pagerbarang Kabupaten Tegal. Pada tanggal 3 Desember 2019 dilaksanakn kegiatan pendidikan kesehatan dan pelatihan pada kader tentang pemeriksaan antopometri dan penilaian status gizi balita, pada pelatihan para kader diberikan suatu aplikasi untuk mendeteksi status gizi balita sehingga dapat dijadikan sebagai usaha deteksi awal stunting. Kedua kegiatan diawali dengan melakukan pre test baik pada ibu balita maupun pada kader kesehatan untuk mengetahui sejauh mana ibu mengetahui gizi tentang balita kader yang terlibat tahu mengenai stunting dan periksa antopometri. Selanjutnya pada ibu balita diberikan penyuluhan tentang gizi balita pada kader kesehatan diberikan pendidikan kesehatan tentang stunting dan dilatih melakukan periksa antopometri pada balita serta bagaimana hitung status gizi balita dengan menggunakan z score.

Selain itu untuk mempermudah para kader dalam menentukan status gizi balita para kader diberika aplikasi yang disebut dengan aplikasi tumbang yang pernah dibuat oleh tim pengabdi kepada masyarakat, dengan aplikasi tersebut setelah para kader memasukkan hasil pemeriksaan antopometri dan usia serta jenis kelamin maka bisa diketahui hasil akhir status gizi.

Pada akhir kegitan tim pelaksana pengabdian pada masyarakat melakukan kegiatan post test untuk mengetahui sejauh mana keberhasilan dari kegiatan yang telah dilaksanakn.

Tabel 1. Peningkatan Pengetahuan Ibu Balita tentang Gizi Balita

\begin{tabular}{llcc}
\hline No & Tingkat Pengetahuan & Sebalum Pendkes & Setelah Pendkes \\
\hline 1. & Baik & 10 & 13 \\
2. & Cukup & 6 & 8 \\
3. & Kurang & 10 & 5 \\
\hline & Jumlah & 26 & 26 \\
\hline
\end{tabular}

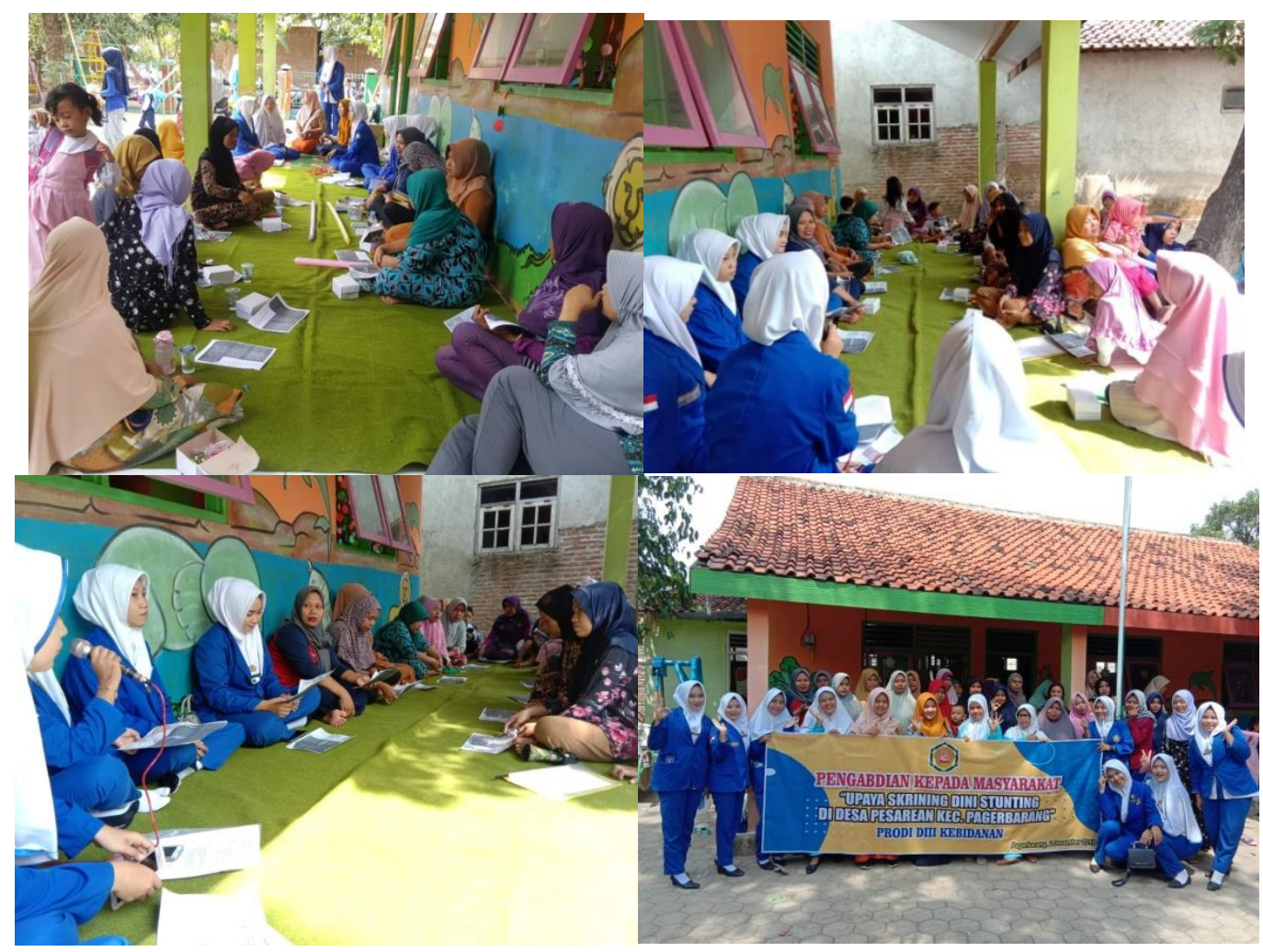

Gambar 1 Dokumentasi Pelaksanaan Kegiatan 


\section{SIMPULAN}

Hasil pengabdian pada masyarakat dalam bentuk Iptek bagi Masyarakat (IbM) yang telah dilaksanakan dapat disimpulkan yaitu terdapat peningkatan pengetahuan ibu balita yang mengikuti kegiatan khususnya peningkatan pengetahuan tentang gizi balita sebagai upaya dalam mencegah stunting pada balita, terdapat peningkatan pengetahuan serta keterampilan kader dalam melakukan pemeriksaan antopometri pada balita dalam upaya melakukan deteksi dini balita yang mengalami stunting.

\section{DAFTAR PUSTAKA}

Bappenas RI. (2012). Pedoman perencanaan program gerakan sadar gizi dalam rangka seribu hari pertama kehidupan (1000 HPK), p 1-8.

Ikatan Dokter Anak Indonesia (IDAI). (2015). Kurva pertumbuhan WHO. Diakses dari http://www.idai.or.id/professional-resources/growth chart/kurvapertumbuhanwho.

Kementerian Kesehatan RI. (2011). Keputusan Menteri Kesehatan Republik Indonesia Nomor 1995/ Menkes/SK/XII/2010 tentang Standar Antopometri Penilaian Status Gizi Anak. Jakarta: Kementerian Kesehatan RI, Direktorat Jenderal Bina Gizi dan Kesehatan Ibu dan Anak, Direktorat Bina Gizi.

Kementerian Kesehatan RI. (2016). Situasi balita pendek. Jakarta: Kementerian Kesehatan RI, Pusat Data dan Informasi.

Kementerian Kesehatan RI. (2017). Profil kesehatan Indonesia. Jakarta. Retrieved from http://www. kemkes.go.id.

Kementerian Kesehatan RI. (2018). Hasil utama Riskesdas 2018. Jakarta.

Millennium Challenge Account - Indonesia. (2018). Stunting dan masa depan Indonesia. Jakarta: MCA - Indonesia.

Ni'mah, K., \& Nadhiroh, S.R. (2015). Faktor yang berhubungan dengan kejadian stunting balita. Media Gizi Indonesia, 10(1).

Notoatmodjo, S. (2012). Ilmu kesehatan masyarakat: Prinsip-prinsip dasar. Jakarta: Rineka Cipta.

Samsudin, S. (2005). Manajemen sumber daya manusia. Bandung: Pustaka Setia.

Sekretariat Daerah Kabupaten Sumedang. (2018). Hasil wawancara terkait stunting di Kabupaten Sumedang.

Tim Nasional Percepatan Penanggulangan Kemiskinan. (2017). 100 Kabupaten/Kota prioritas untuk intervensi anak kerdil (stunting). Jakarta: Tim Nasional Percepatan Penanggulangan Kemiskinan (TNP2K).

UNICEF. (2012). Ringkasan kajian gizi Oktober 2012. Jakarta: UNICEF Indonesia. 
UNICEF. (2013). Improving child nutrition, the achievable imperative for global progress. New York: United Nations Children's Fund.

World Health Organization. (2010). Nutrition landscape information system: Country profile indicators. Geneva, Switzerland: World Health Organization.

World Health Organization. (2018). Reducing stunting in children: equity considerations for achieving the Global Nutrition Targets 2025. 